\title{
INFLUENCE OF SPRING WEATHER CONDITIONS ON BREEDING BIRD DENSITIES IN GTNP
}

\author{
MARTIN L. CODY $\uparrow$ UNIVERSITY OF CALIFORNIA $\uparrow$ LOS ANGELES
}

\section{$\hookrightarrow$}

\section{AbSTRACT}

The thaw came very late to Jackson Hole in 2011 , with snow melt-out on May $15^{\text {th }}$. This year shares with 2008 and 2010 the claim of the latest spring over recent decades. The spring snow meltout is a function of both accumulated snowfall and spring temperatures. A second measure of the advent of spring is the accumulation of growing degree-days (GDD); GDD finally exceeded $225\left({ }^{\circ} \mathrm{F} ; 125{ }^{\circ} \mathrm{C}\right)$ on June $23^{\text {rd }}$, that value being a predictor of $90 \%$ leaf-out in aspens. As is usual in late years, overall species richness and total bird density were generally lower across most park habitats. In particular, the foliage insectivores of the deciduous habitats, such as warblers and vireos in willows, aspens and cottonwoods, were much reduced in density (by as much as 50\%). Sagebrush habitats, where snow persists longer in late springs and where most species feed on the ground early in the breeding season, were the most impoverished. In two such monitoring sites, \#4 (Jackson Lake Junction Grass-sage) and \#6 (Airport Sage), there were $1 / 4$ to $1 / 3$ fewer species present respectively, and bird densities were reduced to $43 \%$ and $39 \%$ of long-term averages for the sites.

\section{$\uparrow \quad$ INTRODUCTION}

The timing of spring events that signal the advent of a new breeding season and allow birds to choose and defend the locations where they will attempt to raise young is an important variable. How early the breeding season can start may determine how many breeding attempts are possible during the season, which in turn can have pivotal population effects on short-lived species with few breeding opportunities. In high-latitude and/or high-elevation locations, reasonably descriptive of Grand Teton Nation Park (GTNP), the breeding season may already be critically short, with adverse conditions in late spring and early fall constraining a short summer season. For migrant birds, the predominant species in short breeding season locations, the timing of their returns from wintering areas to summer breeding sites is an evolved, behavioral trait adapted to the average onset of conditions suitable for initiation of breeding, and the progression of the vegetation and food supplies that they imply. Thus, generally, migrant birds will not be able to make full use of early springs by beginning breeding earlier, although they may reap the advantages of elevated food levels, and possibly lay and raise larger clutches. On the other hand, both residents and migrants will be particularly disadvantaged by late springs that necessitate delayed reproduction and a shorter season. While resident populations will bear those costs, migrants may choose to seek suitable conditions elsewhere or over a wider geographical area rather than wait locally for productivity to ameliorate.

Spring conditions in GTNP are described simply by the average temperature and the total precipitation from March to May inclusive, SPRT and SPRP. Since 1950, SPRT has averaged $34{ }^{\circ} \mathrm{F} \pm$ 2.5SD (see Figure 1), and ranged from a high of almost $42{ }^{\circ} \mathrm{F}$ to a low of $29.3^{\circ} \mathrm{F}$. Over the same $62 \mathrm{y}$ time period, SPRP has varied much more widely, about six-fold, with a mean of $6.1 " \pm 2.0 \mathrm{SD}$, a high value of $>12.0$ " and a low of $<2.0$ ". Over this time interval, there has been no discernible trend in spring precipitation that is statistically robust, although there has been a tendency for spring precipitation to be 
somewhat more variable over the last three-quarters of the record. Comparing years $<1986$ and $>1985$, unpaired samples t-test yields $t=-1.25, p=0.218$. A series of six years of generally declining spring precipitation ended in 2008, and in 2011 the precipitation was the highest recorded during the $62 \mathrm{y}$ interval.

Spring temperatures, while generally steadier than precipitation totals, do show a statistically significant trend, with higher temperatures higher in years 1986-2011 than in the earlier years 1950-1985 (unpaired samples, 2-tailed ttest, $\mathrm{t}=-5.14, \mathrm{p}<0.001)$. This observation is in accord with the widely-recognized warming trend recorded over the western U.S. over the last 30+ years, over which GTNP spring temperatures have increased by some $2.8^{\circ} \mathrm{F}\left(1.6^{\circ} \mathrm{C}\right)$.

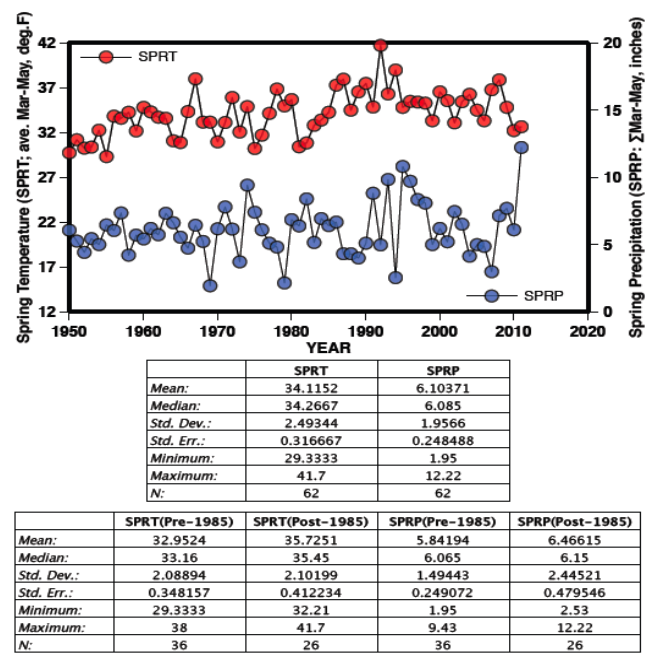

Figure 1. A sixty-two year record of spring (March-May) average temperature SPRT and total spring precipitation SPRP at Larry Robinson's Jackson Lake Dam weather station. Summary statistics are given in the charts below, including separate summary figures for years pre- and post 1986; see text for further analysis.

Birds are likely to respond directly to environmental cues other than temperature and precipitation, particularly to cues associated with weather conditions in the recent past. Leaf-out of the deciduous trees and shrubs, such as willows, aspens and cottonwoods, will essentially reflect cumulative conditions throughout an advancing spring. Leaf-out may provide the cues for habitat selection based vegetation structure, and also signal food resource availability, since herbivorous insect activity will be tightly correlated with leaf-out dates. Another obvious environmental cue for birds seeking breeding sites is the presence or absence of snow on the ground. This variable also is a cumulative picture of past spring conditions, both temperature and precipitation, during the seasonal advance from winter toward summer. Snowpack depth will clearly affect what exposed vegetation serves as foraging sites for early spring birds, and how melting snowpack of decreasing depth would reveal bird breeding habitats, in sequence, from willows, then sagebrush, then grass- and sedge-land, in GTNP. Snow that persists late into the spring is particularly critical for ground-foraging birds, a large category that includes both passerines such as sparrows, larks, blackbirds and corvids, as well as non-passerines such as cranes, geese, plovers and sandpipers. I refer to two variables that indicate the earliness or lateness of spring in GTNP: First, the snow meltout date (SMOD), measured below Jackson Lake Dam at the Moran $5 \mathrm{WNW}$ weather station, is the Julian date at which the snowpack has dwindled to zero; it averages APR 19. Second, the leaf-out date, measured by the Julian date by which growing degree-days (GGD) has reached a value of $125\left({ }^{\circ} \mathrm{C}\right)$ or $225\left({ }^{\circ} \mathrm{F}\right)$, averages JUN 8 at Moran 5 WNW. GDD 125 is established in the literature as the degrees $>5{ }^{\circ} \mathrm{C}$ (accumulated over days) that predicts $90 \%$ leaf-out in aspens Populus tremuloides.

Both variables, SMOD and GDD125, include aspects of spring temperature and spring precipitation, but different aspects, since they are but weakly correlated $\left(r=-0.36, R^{2}=13 \%\right.$; see Figure. 2).

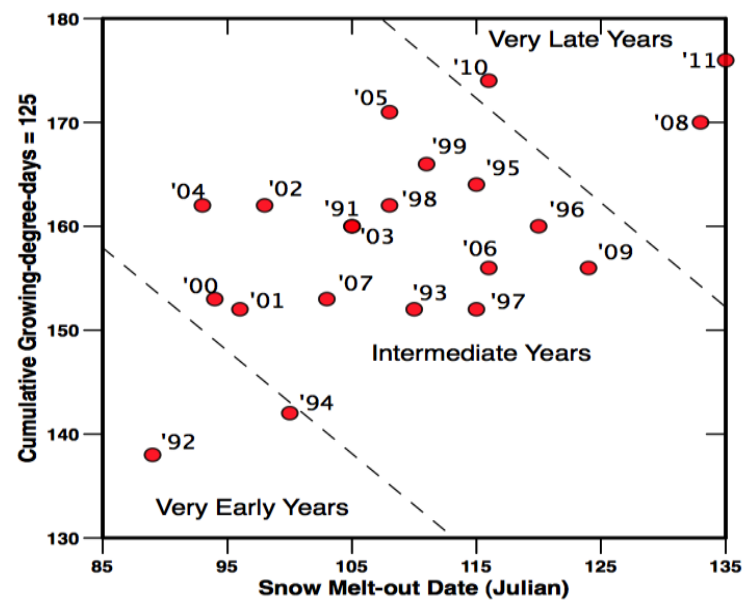

Figure 2. Variation in two relatively independent indicators of the arrival of spring in GTNP. a) Julian date of GDD125 (ordinate: the number of growing degree-days [125] required for $90 \%$ leaf-out in aspens), and b) SMOD (abscissa: Julian date by which the winter snowpack dwindles to zero near Jackson Lake Dam). Only oneeighth of the variation in one of these variables is accounted for by variation in the other. SMOD is related more to spring precipitation that temperature, whereas the reverse is true for GDD125. 
SMOD is inversely correlated to SPRT $(r=-$ $0.43)$, and more strongly related to SPRP ( $\mathrm{r}=0.59)$. GDD125, as one might expect, is closely related to spring temperatures $(r=-0.729)$, but also it increases (i.e. delayed leaf-out) with increased precipitation $(r$ $=0.395)$. Thus, there are two sorts of late springs, one driven largely by high precipitation (SMOD) and another related to slow spring warming rates (GDD125). Note that, over the years, there is a $40 \mathrm{~d}$ variation between the earliest and latest aspen leafout dates, and a similar interval between the earliest and latest snow melt-out dates. Note also that the three very late springs (upper right in Figure 2) fall in the last four years.

\section{$\uparrow \quad$ Methods, Study Sites, Concepts}

For the purposes of this report, I use longterm breeding bird census data from four of the ca. 30 sites in GTNP for which such data exist. The rationale for this particular selection is that these four sites are within $1 \mathrm{~km}$ of the weather station site near Jackson Lake Dam, secondly that the four sites are within $0.5 \mathrm{~km}$ of each other, and thirdly that they represent quite different habitat types, all of which are important to the vegetational diversity of GTNP. The sites are, respectively, Site \#2: Jackson Lake Junction (JLJ) Grass-sedge-field; Site \#4: JLJ GrassSage; Site \#10: JLJ Wet Willows, and Site \#11: Oxbow Aspen-Willow. They have been censused in $18,21,20$, and 19, respectively, of the 21 years since 1991. The census data record which species are using the site in a specific year, and how many pairs are breeding within the site. The census protocols were established at the time of initial selection of the sites, early 1990s, and have been followed since that time; previous reports to the Research Center will specify those details.

Table 1 lists 20 common bird species that breed in the selected four study sites, about half of them breeding in more than one site of the sites. The database on breeding densities over the years will be used to test hypotheses about which species and which habitats might show responses, via shifts in breeding densities, to variation in spring's advent as measured by SMOD and GGD125 dates.

Of course, bird breeding densities are likely influenced by a plethora of factors beyond whether spring arrives early or late. Some of these, amongst many others, are last season's reproductive output, overwintering success, the state of the vegetation and the food resources it produces, the level or proximity of predation threats, pressures from competitors, and disturbances both natural and unnatural. Therefore, any effects from the timing of spring are likely to be masked, to a greater or lesser extent, by other processes and pressures in the breeder's environment. This means that relationships, if they exist, are expected to be loose or imprecise, and discernible if at all by primitive statistical standards. Some possibilities are illustrated in Figure 3, where ordinates correspond to breeding density of a species, and abscissas are measures of spring timing, SMOD or GDD125. In Figure 3, parts A and B depict generally positive and negative relationships (densities increasing and decreasing, respectively, with the lateness of the spring season. In parts $\mathrm{C}$ and $\mathrm{F}$, high densities occur only with late seasons, with early seasons precluding the lowest densities (C) or the highest densities $(\mathrm{F})$. In parts $\mathrm{D}$ and $\mathrm{E}$, high densities are recorded in years with early spring seasons, and late seasons preclude (D) or allow (E) some high density counts.

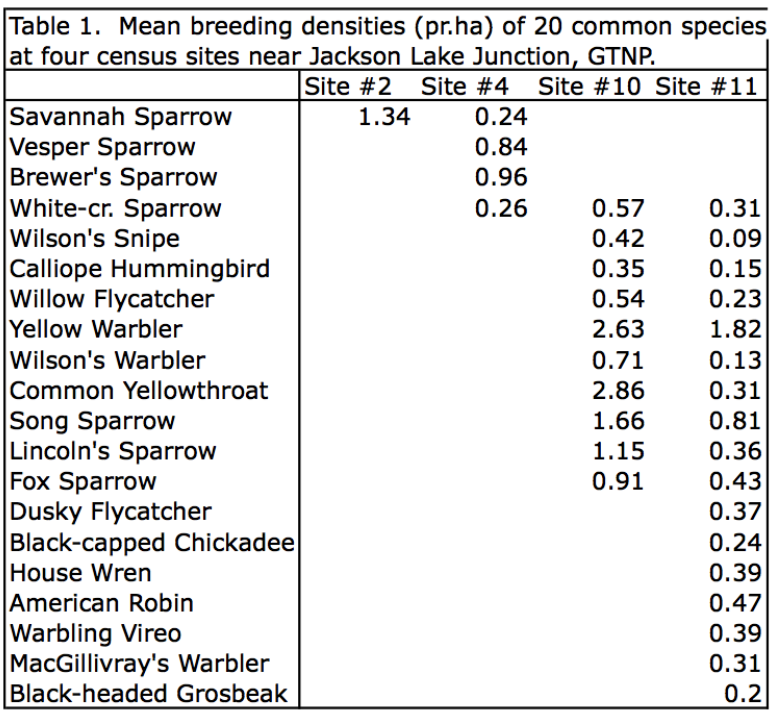
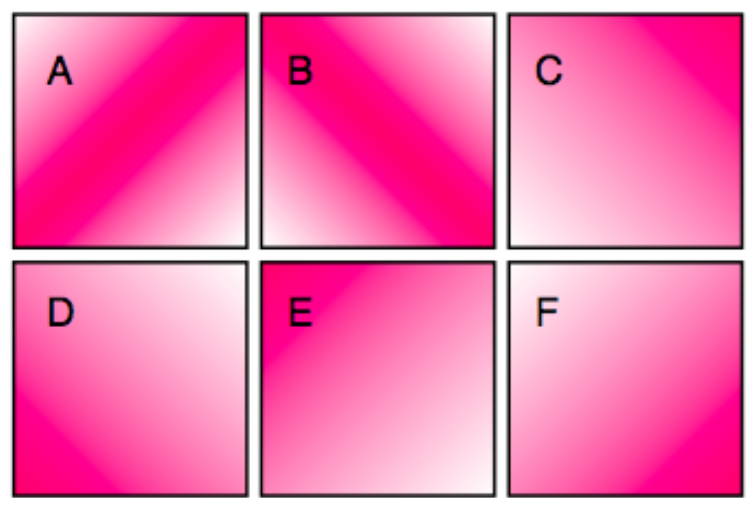

Fig. 3. Possible patterns of breeding density (ordinate) as a function of the advent of spring events (abscissa), early on the left to late on the right. See text for discussion. 


\section{$\downarrow \quad$ RESULTS}

\section{Species Unaffected by Spring Timing}

There are a number of species in Table 1 that are evidently not influenced by the timing of spring. Not included in Figure 3 is the null option, in which there is no support for the hypothesis that the timing of spring affects breeding densities. The reality of this option is reinforced by species that occur in two different habitats, in neither of which is there any clear pattern in density and spring timing. Calliope Hummingbird Stellula calliope, Willow Flycatcher Empidonax traillii, Wilson's Warbler Wilsonia pusilla, and Song Sparrow Melospiza melodia all breed in both sites 10 and 11, and are examples of the null option. In addition, Vesper Sparrow Pooecetes gramineus of Site 4, and Black-headed Grosbeak Pheuticus melanocephalus, House Wren Troglodytes aedon, Black-capped Chickadee Poecile atricapillus, and MacGillivray's Warbler Oporornis tolmiei of site 11 also vary year-to-year in breeding densities, but they do so without relation to spring timing. The only common species of Site 2, the grass-sedge field, is Savannah Sparrow Passerculus snadwichensis, and while it varies in breeding density $>3$-fold among years $(0.65-2.20 \mathrm{pr} / \mathrm{ha})$, this variation is not related to the timing of spring. Willow Flycatcher densities in sites 10 and 11 are plotted against SMOD and GDD in Figure 4.

Willow Flycatcher, like its congener Dusky Flycatcher, is a long-distance migrant, as are the two warblers, the hummingbird, and grosbeak, while the sparrows (Song, Vesper, Savannah) are shorter distance migrants, the first mentioned even wintering locally; the chickadee is a year-round resident.

\section{Species with Density Responses to a Single Spring Timing Measure}

Two of the species tested (Table 1) respond to a single measure of spring timing, GDD125, and not at all to the second measure (SMOD). These are Common Yellowthroat Geothlypis trichas and Wilson's Snipe (Gallinago delicata), both species of wetlands. These wetlands remain wet even in dry years, and this may account for an independence from SMOD, which is largely determined by spring precipitation. Wilson's Snipe, in both sites 10 and 11, display higher breeding densities in late years than in early years (Figure 5); the pattern is similar for Common Yellowthroat. Here breeding density has been standardized for each census site, since snipe densities average $4 \mathrm{X}$ higher at Site 10 than at Site 11 (nine times higher for the yellowthroat). Why these two species, sharing little except a preference for wetlands as a breeding habitat, should both respond positively to late years invites speculation. Both are migrants, with the snipe wintering in the southern United States into Mexico, the yellowthroat from Mexico south into Central America. One possibility, quite without any solid foundation, is that migrants returning north are "siphoned off" into productive habitats as they are encountered. As GTNP is fairly close to the southern end of the breeding range in the central U.S., perhaps the option of moving further north in late springs is less attractive, with the result that birds are retained in the southern parts of the range to a greater extent than in early spring years. The assumption that a late GTNP spring corresponds to a late spring in e.g. the Yukon remains to be tested.

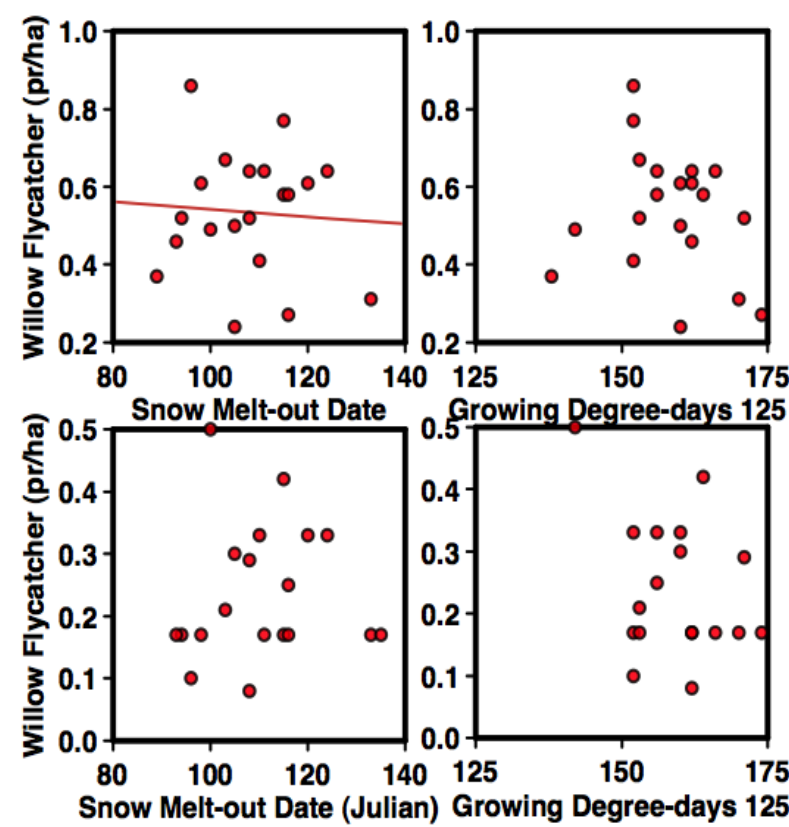

Figure 4. Breeding densities of Willow Flycatcher as a function of SMOD (left) and GGD125 (right); neither independent variable affects the flycatcher's breeding density.

One other species has a distinct density response to one measure of spring timing, SMOD, but not to the other-GDD125. Brewer's Sparrow Spizella breweri is often the commonest breeding bird in the grass-sage of Site 4 , but in years with late snow melt-out the species can be entirely absent. Zero density counts have been recorded at Site 4 for Brewer's Sparrow five times since 1991. The plot of density vs. SMOD is highly significant for this species, as shown in Figure 6. Note that, in locations where SMO dates are earlier, as in the southern end of Jackson Hole (e.g. near the Moose weather station; over a week earlier), Brewer's Sparrow densities (e.g. 
at Site 6, Airport Sage) are not nearly as sensitive to SMOD as they are at Site 4, at the northern end of the Hole. On the Antelope Flats road east of Blacktail Butte, Site 5 census data reveal that dependence on SMOD there is intermediate between Moran and the Airport.

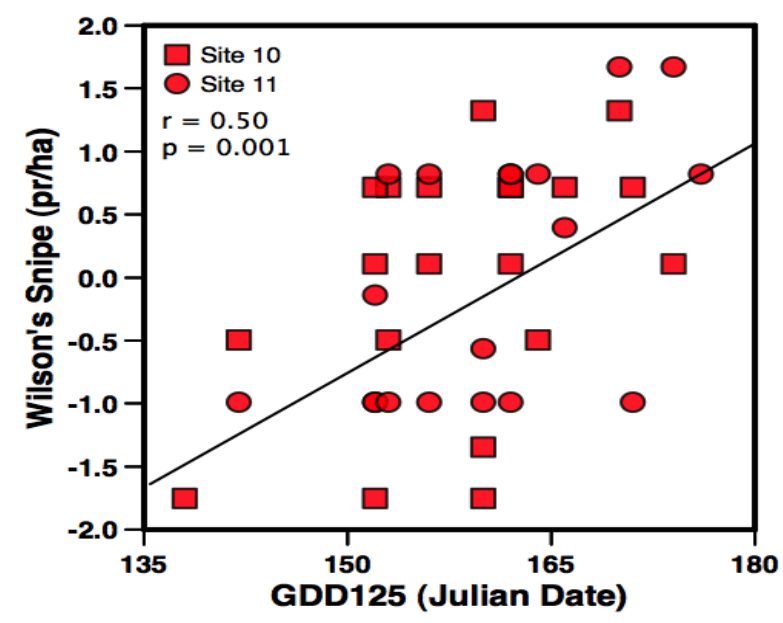

Figure 5. Standardized breeding densities of Wilson's Snipe in sites 10 and 11, as a function of GGD125. Snipe are present at significantly higher densities in late springs.

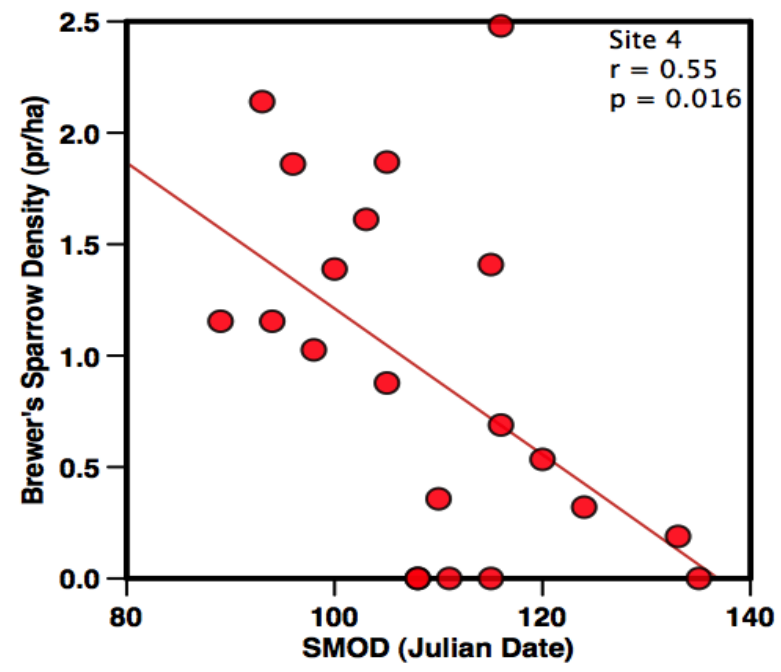

Figure 6. Brewer's Sparrow breeding densities in Site 4 show a strong dependence on snow melt-out dates (SMOD); the species is rare or absent in late years.

\section{Species with Density Responses to Spring Timing in One Habitat but Not Another.}

Several species in Table 1 show a density response to the timing of spring events in one GTNP habitat, but not in another. Examples are three species that breed in Site 11, Aspen-Willows, where their densities are independent of measures of spring timing, and breed also in Site 10, the Wet Willows, where they all have been recorded at lower densities in late springs, whether measured by SMOD or GDD125, and in greater numbers in earlier springs. These are Lincoln's Sparrow Melospiza lincolnii, Fox Sparrow Passerella iliaca, and White-crowned Sparrow, Zonotrichia leucophrys. All three species forage on the ground, a behavior not feasible before snow melt-out (average Moran date APR 19), and presumably more productive in years of higher spring temperatures that accelerate insect productivity at ground level (lower GDD125; average Moran date JUN 8). Again speculatively, it would seem that habitats with taller vegetation (i.e. aspens at Site 11) would become occupiable by these sparrows earlier in the year than lower willows-dominated habitats. In mid-winter, only the bare tops of a few of the taller willows reach above the level snowpack in Site 10, whereas in Site 11 the snow depths are much more variable, and the trees provide various opportunities for snow-free or at least snow-shallow areas, which melt out sooner and permit sparrow foraging earlier. Such a difference might explain why the several sparrow species are adversely affected by late springs in the willows but not in the aspens.

Song Sparrow is a breeding species in both of these habitats (Sites 10, 11), but its densities are not responsive to the timing of spring (see above). In GTNP, Song Sparrows are found almost exclusively along water courses, especially the shallow drainage channels that run through both Sites 10 and 11. These habitat features are apparently hospitable to the sparrows even where the surrounding snowpack remains or vegetative regrowth is delayed by low temperatures.

One other emberizine, Savannah Sparrow, shows early spring effects (enhanced densities) in one habitat but not another. In Site 2 no such effects have been detected, but in Site 4, a sagebrush-grassland mix that is much drier than Site 2, Savannah Sparrows are common in years of early springs, but in late springs, when the grass component they preferentially select has barely begun to grow by mid-summer (e.g. in 2011; Cody 2013), Savannah Sparrows are scarce or absent. Figure 7 illustrates decreasing breeding densities with later spring timing in Savannah and Fox Sparrows, at Sites 4 and 10 respectively. These plots are typical of those of the other species mentioned in this section. In Fox Sparrow, White-crowned and Lincoln's Sparrows, SMOD may be substituted for GDD with the same result (negative slope), but not so in Savannah Sparrow. Another species of Site 11, American 

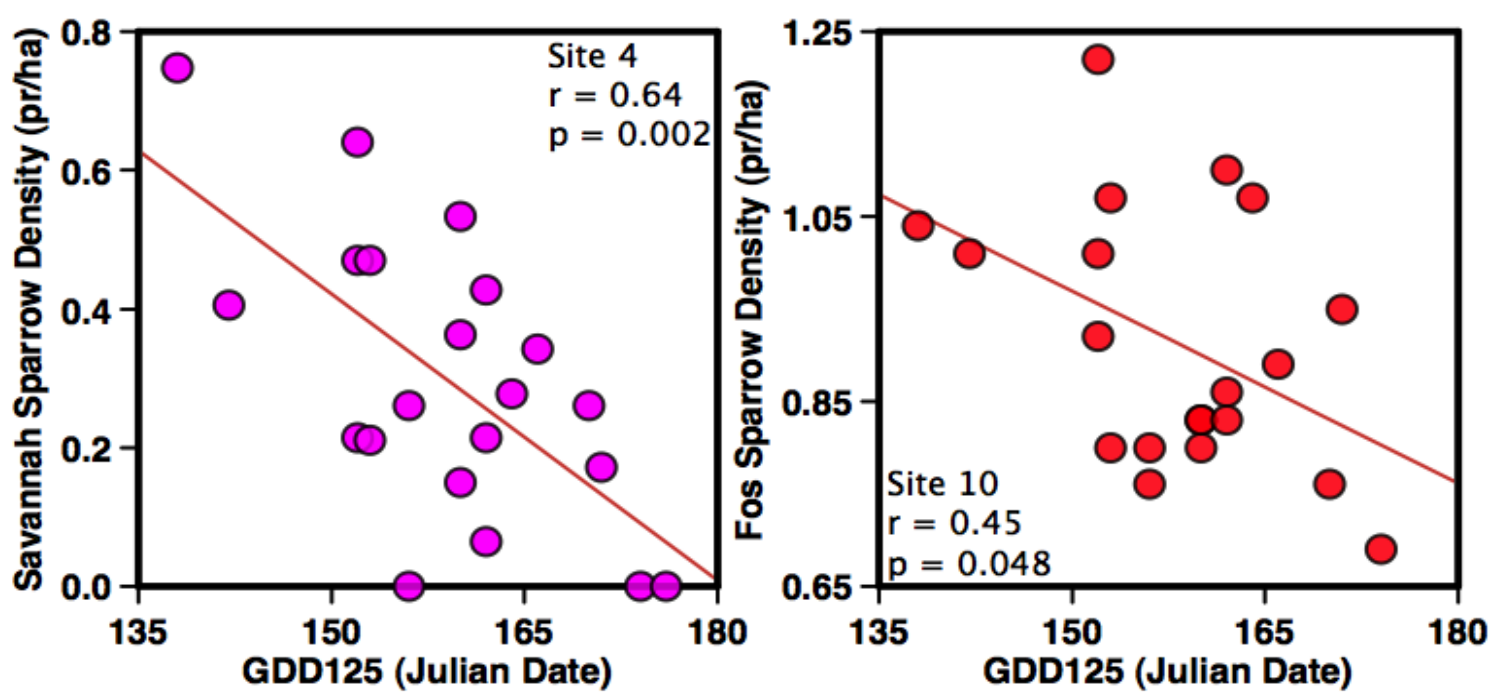

Figure 7. Breeding densities of Savannah Sparrow (left) and Fox Sparrow (right), in Sites 4 and 10 respectively, increasingly decline with the lateness of the arrival of spring.

Robin Turdus migratorius, also a ground foraging species, responds similarly to both measures of spring timing, SMOD and GDD125. In years with SMOD <105 (Julian Date; $\mathrm{n}=7$ ), robin densities at the site average $0.45 \pm 0.081 \mathrm{pr} / \mathrm{ha}$, whereas in the 7 years with the latest SMOD values the robins reached an average density of just $0.299 \pm 0.189 \mathrm{pr} / \mathrm{ha}(\mathrm{t}=$ 1.99 ; df $=12, \mathrm{p}=.069$ ). In 2011, with the latest SMOD in the last $25 \mathrm{y}$, no robins bred at Site 11; clearly, robins do better when spring arrives early.

\section{Species with Non-linear Density Responses: Higher Numbers in Average Years.}

The last pattern to be mentioned here is of species that exhibit their highest densities in average years. This is characteristic of species that a) are long-distance migrants, such as Yellow Warbler Dendroica petechia and Warbling Vireo Vireo gilvus, and b) are foliage insectivores and thus dependent on foliar insects, the availability of which is in turn regulated by the leaf-out dates of the deciduous habitats in which these birds are predominant: willows, aspens, and cottonwoods. The optimal strategy for migrant birds with a strong dependence on foliage insects is to time their return to breeding habitats coincident with the average leaf-out date of the vegetation, and a broad literature attests to this. The subject was discussed by Cody (2011), and thus will not be developed here.

\section{$\uparrow \quad$ CONCLUSION}

While the density responses of bird species to the timing of spring are varied, over species, habitats, and foraging behaviors, the dominant pattern among the GTNP breeding birds is decreased densities in years of later springs. Thus, it would seem that the warming trend predicted to continue for many decades over western North America, and evidenced in GTNP by elevated spring temperatures, will, at least initially, be beneficial to many of the Park's birds.

\section{$\uparrow \quad$ Literature Cited}

Cody ML. 2011. Variation in the date of Leaf-out in Jackson Hole's deciduous habitats: effects of late spring on breeding birds. In: H.J. Harlow M.A. Harlow, editors. University of Wyoming - National Park Service Research Center, Grand Teton National Park, 30th Annual Report 2009

Cody ML. 2013. Birds in Seasonal Environments: Breeding Birds Populations Grand Teton National Park. 550 pp MS in review 